\title{
Radiation Degradation of Silicon Crystal Used as Filter for Neutron Radiography
}

\author{
Ladislav Viererbl ${ }^{a}{ }^{*}$, Jaroslav Šoltés, Miroslav Vinš, Hana Assmann Vratislavská \\ and Alexander Voljanskij
}

Research Centre Rez Ltd., Hlavní 130, Husinec-Řež, 250 68, Czech Republic

a ladislav.viererbl@cvrez.cz

\section{Keywords: Radiation Degradation, Neutron Filter, Silicon Crystal, Neutron Radiography}

\begin{abstract}
Single crystals of some materials like silicon, sapphire or bismuth are often used as radiation filters for neutron radiography beams. These single crystals are relatively transparent for thermal and cold neutrons and can suppress fast neutrons and gamma radiation. When a single crystal is irradiated the crystal lattice is partially damaged and filter characteristics of the crystal can be deteriorated. This aspect of radiation degradation was studied for silicon single crystals. Experiments for silicon radiation degradation measurements were carried out in the LVR-15 research reactor. A silicon crystal sample (length of $10 \mathrm{~cm}$ ) was irradiated in the reactor core. Thermal neutron attenuation was measured on the thermal neutron beam used also for neutron radiography facility. The attenuation measurement was made by activation detectors before and after crystal irradiation in the reactor core. A silicon single crystal (length of $100 \mathrm{~cm}$ ) is used as a neutron filter in the channel used for neutron radiography in the LVR-15 reactor. The results indicate that the radiation degradation of the filter is acceptable low for a few years of facility operation.
\end{abstract}

\section{Introduction}

Horizontal channels of research reactors can be used for neutron radiography. To optimize the neutron beam parameters, filters are inserted into the channel. Single crystals of some materials like silicon, sapphire or bismuth are often used as radiation filters for neutron radiography based on thermal or could neutron beams [1,2]. These crystals are relatively transparent for thermal and cold neutrons and can suppress undesirable fast neutrons and gamma radiation emitting from a reactor core. Cross sections for thermal neutrons of these single crystals are 5 to 10 times lower [3] compared with amorphous or polycrystalline samples of the same materials [4]. When the single crystal is irradiated the crystal lattice is partly damaged and filter characteristics of the crystal can be deteriorated. Here this aspect of radiation degradation was studied for silicon single crystals. Attenuation increasing due to irradiation was measured for thermal neutrons. According the theory, attenuation parameters for fast neutrons and gamma radiation change insignificantly compare to thermal neutrons. During neutron irradiation of a silicon single crystal, defects in the crystal lattice are induced by two main ways: ${ }^{30} \mathrm{Si}$ nuclide is transmuted to ${ }^{31} \mathrm{P}$ by $\mathrm{n}-\gamma$ reaction and $\mathrm{Si}$ nuclei are displaced by fast neutron scattering on the nuclei and produce crystal defects. The second type of induced defects can be partly removed by annealing of the crystal.

\section{Silicon crystal irradiation}

Experiments for silicon single crystal radiation degradation were carried out in the LVR-15 research reactor [5], which is a multipurpose facility with nominal thermal power of $10 \mathrm{MW}$, situated in Řež near Prague. One horizontal channel denoted as HC1 (Fig. 1) is used for neutron radiography facility where cylindrical silicon single crystal with diameter of $78 \mathrm{~mm}$ and 
$1000 \mathrm{~mm}$ long is inserted into the channel as neutron filter (Fig. 2). The channel is radial type and the facility use multipixel detector placed in the beam axis. Therefore relatively large crystal is needed to significantly suppress undesirable fast neutrons and gamma radiation.

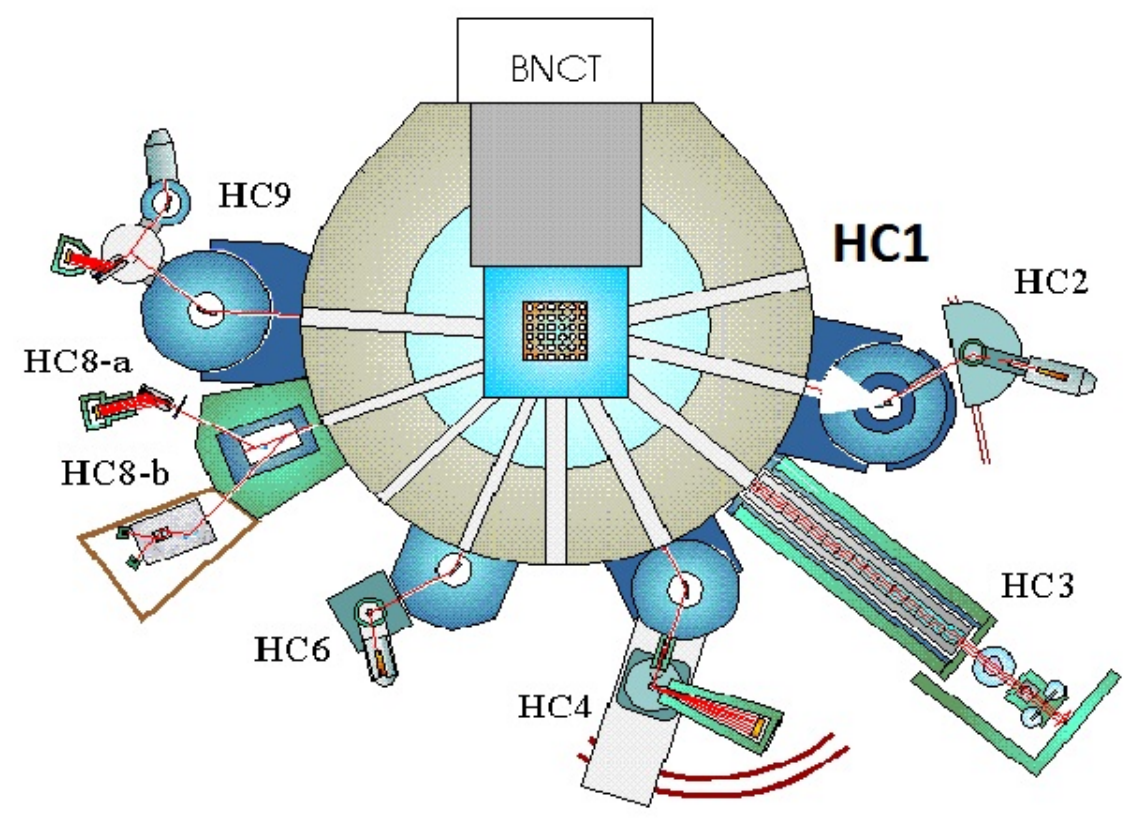

Figure 1. Horizontal channel layout at the LVR-15 research reactor. The channel chosen for the neutron radiography facility is denoted as HC1 [6].

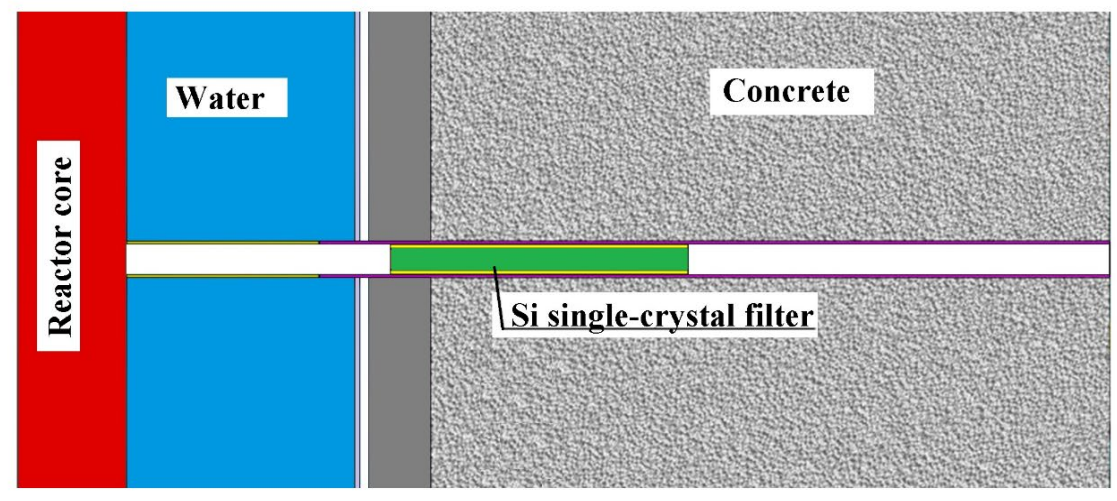

Specimen location

Figure 2. Cross-section of the HC1 horizontal channel with the location of the silicon single crystal used as neutron filter [7].

During reactor operation the silicon crystal used for filter in the horizontal channel HC1 is permanently irradiated from reactor core. In the position of silicon cylinder base faced to reactor core (beginning of the filter), the average neutron fluence rate is estimated to about $8 \times 10^{17} \mathrm{~cm}^{-2} /$ year.

For the radiation degradation experiment, a silicon single crystal cylindrical sample $(\phi 78 \mathrm{~mm} \times 100 \mathrm{~mm})$ was used. The sample was irradiated in a vertical channel DONA [5] close to the core of the LVR-15 reactor. During one day irradiation, the sample received total fluence 
of $7.6 \times 10^{17} \mathrm{~cm}^{-2}$. Then irradiation fluence is roughly equal to the fluence, which the beginning of the filter in the horizontal channel HC1 receives per year.

\section{Thermal neutron attenuation measurement}

Thermal neutron attenuation in the silicon single crystal sample was measured before irradiation in the reactor core and after the irradiation. Neutron attenuation was measured on the LVR-15 neutron radiography beam, which is thermal neutron beam on HC1 horizontal channel, the same as discussed in the above chapter. The silicon sample with detectors were irradiated in the beam on "Specimen location" in Fig. 2. The neutron fluence received during this measurement was negligible compare with the fluence in the reactor core described above. Three types $(\mathrm{Cu}, \mathrm{In}, \mathrm{Au})$ of activation detectors were used. Two sets of detectors were on front face of the silicon sample (Fig. 3 Left) and two sets on the rear face. Activated radionuclides have short half-life then the same detectors were used for both attenuation measurement (before and after irradiation in reactor core) to avoid some uncertainties, e.g. in detector weighting. Silicon cylinder axis was parallel with the beam and the detectors were fixed on both cylinder bases (Fig. 3 Right). Activation detectors were $\phi 10 \mathrm{~mm} \times 0.1 \mathrm{~mm}$ foils. Materials were pure $\mathrm{Cu}$ and $1 \%$ alloy based on aluminium for In and Au.
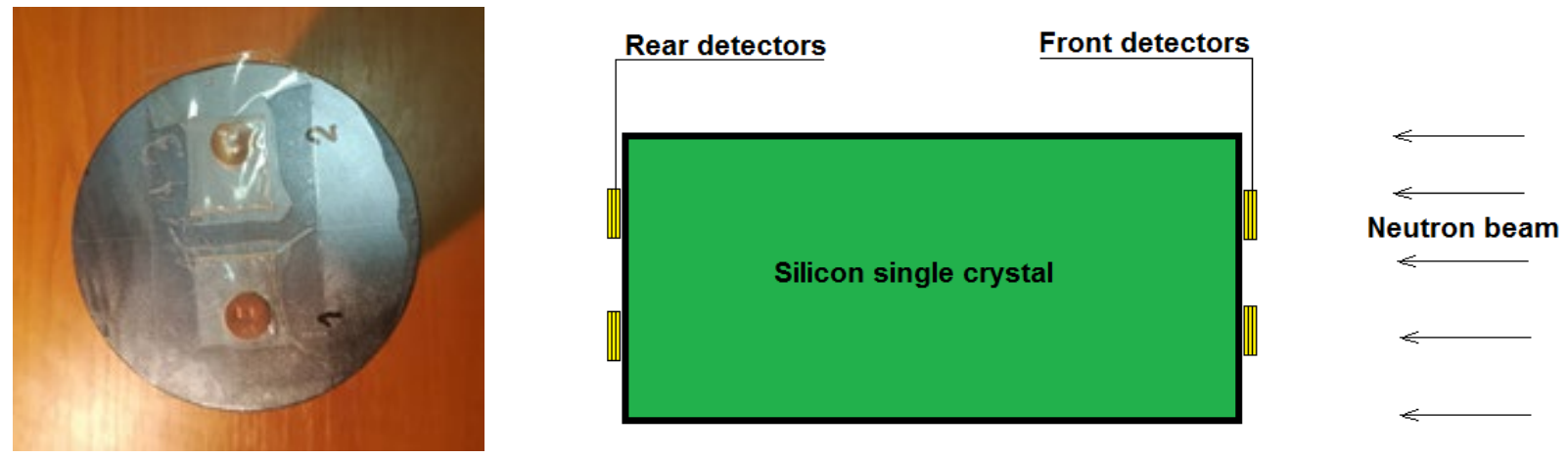

Figure 2. Left - photo of Si crystal cylinder base with fixed activation detectors. Right - arrangement of thermal neutron attenuation measurement.

The silicon sample with the activation detectors was irradiated in the HC1 beam during 24 hours. Then HPGe detector was used for activity measurement [8]. For the attenuation evaluation, neutron capture nuclear reactions were used: ${ }^{63} \mathrm{Cu}(\mathrm{n}, \gamma){ }^{64} \mathrm{Cu}$ for $\mathrm{Cu}$ activation detectors, ${ }^{197} \mathrm{Au}(\mathrm{n}, \gamma){ }^{198} \mathrm{Au}$ for $\mathrm{Au}$ and ${ }^{115} \operatorname{In}(\mathrm{n}, \gamma){ }^{116 \mathrm{~m}} \mathrm{In}$ for In detectors. From activity values, reaction rates ( $R R$ - probability of the reaction per one target atom and per second) were calculated [9] and these were used for attenuation evaluation.

Neutron attenuation $C_{i j}$ of the silicon single crystal was calculated according the formula:

$$
C_{i j}=\frac{R R_{R i j}}{R R_{F i j}}+D
$$

where $R R_{P i j}$ are reaction rates, index $P$ means front $(F)$ or rear $(R)$ position, index $i$ lower (1) or upper (2) position (see Fig. 2 Left) and index $j$ represents type of detector $(\mathrm{Cu}, \mathrm{In}, \mathrm{Au})$. The beam is slightly divergent [7] and $D$ expresses correction on the beam divergency. Then one attenuation measurement gives six $C_{i j}$ values and their mean value can be taken as final value $C$. 


\section{Results}

Table 1 shows reaction rates measured before and after silicon sample irradiation in the reactor core. Correction on the beam divergency was evaluated from space distribution of beam fluence rate [7] with result $D=0.059$. From reaction rates and $D$, attenuation values $C_{i j}$ were calculated according Eq. 1 and the values are in Table 2. Relative difference between attenuations before and after irradiation in the reactor core are in last column of the Table 2, six values from six pairs of the detectors and the mean value. After irradiation, attenuation of the silicon sample decreased (deteriorated) from 0.802 to 0.785 , i.e. relatively by $2.2 \%$. Uncertainty $1 \sigma$ of the relative difference was estimated from distribution of individual values with result $0.4 \%$.

Table 1. Measured reaction rates before and after irradiation in the reactor core for six pairs of activation detectors.

\begin{tabular}{|c|c|c|c|c|c|}
\hline \multicolumn{2}{|c|}{} & \multicolumn{4}{|c|}{ RR $_{\text {Pij }}[1 / \mathrm{s}]$} \\
\cline { 3 - 6 } \multicolumn{2}{|c|}{} & \multicolumn{2}{|c|}{ Before irradiation } & After irradiation \\
\hline $\begin{array}{c}\text { Detector } \\
\text { type }\end{array}$ & Position & Front & Rear & Front & Rear \\
\hline \multirow{2}{*}{ In } & 1 & $1.14 \mathrm{E}-14$ & $7.94 \mathrm{E}-15$ & $1.02 \mathrm{E}-14$ & $6.96 \mathrm{E}-15$ \\
\cline { 2 - 6 } & 2 & $1.10 \mathrm{E}-14$ & $8.36 \mathrm{E}-15$ & $9.89 \mathrm{E}-15$ & $7.38 \mathrm{E}-15$ \\
\hline \multirow{2}{*}{$\mathrm{Au}$} & 1 & $4.32 \mathrm{E}-15$ & $3.17 \mathrm{E}-15$ & $6.28 \mathrm{E}-15$ & $4.43 \mathrm{E}-15$ \\
\cline { 2 - 6 } & 2 & $4.27 \mathrm{E}-15$ & $3.32 \mathrm{E}-15$ & $5.95 \mathrm{E}-15$ & $4.49 \mathrm{E}-15$ \\
\hline \multirow{2}{*}{$\mathrm{Cu}$} & 1 & $3.07 \mathrm{E}-14$ & $2.17 \mathrm{E}-14$ & $2.84 \mathrm{E}-16$ & $1.98 \mathrm{E}-16$ \\
\cline { 2 - 6 } & 2 & $2.96 \mathrm{E}-14$ & $2.32 \mathrm{E}-14$ & $2.66 \mathrm{E}-16$ & $2.05 \mathrm{E}-16$ \\
\hline
\end{tabular}

Table 2. Attenuation values and relative differences between attenuations measured before and after irradiation in the reactor core.

\begin{tabular}{|c|c|c|c|c|}
\hline \multirow{2}{*}{$\begin{array}{c}\text { Detector } \\
\text { type }\end{array}$} & Position & $\begin{array}{c}\text { Before } \\
\text { irradiation }\end{array}$ & $\begin{array}{c}\text { After } \\
\text { irradiation }\end{array}$ & $\begin{array}{c}\text { Relative } \\
\text { difference } \\
{[\%]}\end{array}$ \\
\hline \multirow{2}{*}{ In } & 1 & 0.758 & 0.741 & -2.20 \\
\cline { 2 - 5 } & 2 & 0.816 & 0.806 & -1.29 \\
\hline \multirow{2}{*}{$\mathrm{Au}$} & 1 & 0.793 & 0.764 & -3.63 \\
\cline { 2 - 5 } & 2 & 0.838 & 0.813 & -2.90 \\
\hline \multirow{2}{*}{$\mathrm{Cu}$} & 1 & 0.767 & 0.754 & -1.78 \\
\cline { 2 - 5 } & 2 & 0.842 & 0.830 & -1.36 \\
\hline \multicolumn{2}{|r|}{ Mean values } & $\mathbf{0 . 8 0 2}$ & $\mathbf{0 . 7 8 5}$ & -2.19 \\
\hline
\end{tabular}

\section{Conclusion}

Silicon single crystal sample was irradiated in the reactor core to neutron fluence roughly equal to the value, which the beginning of the filter in the horizontal channel for neutron radiography receives per year. Thermal neutron attenuation was measured before and after the irradiation. The attenuation of the crystal decreased by $2.2 \% \pm 0.4 \%$. This change is small but some radiation degradation was proved. In any case, the degradation of the filter in the LVR-15 
neutron radiography facility is acceptable low for a few years of facility operation. This result can be also used for similar silicon filter applications.

\section{Acknowledgement}

The presented work has been realized within Institutional Support by Ministry of Industry and Trade. Presented results were obtained with the use of infrastructure Reactors LVR-15 and LR-0, which is financially supported by the Ministry of Education, Youth and Sports - project LM2015074.

\section{References}

[1] B. M. Rustad, Single-crystal filters for attenuating epithermal neutrons and gamma rays in reactor beams, Review of Scientific Instruments, Vol. 36 (1965) 48-54. https://doi.org/10.1063/1.1719323

[2] R. M. Brugger, A single silicon thermal neutron filter, Nuclear Instruments and Methods, Vol. 135 (1976) 289-291. https://doi.org/10.1016/0029-554X(76)90175-0

[3] A. K. Freund, Cross-sections of materials used as neutron monochromators and filters, Nuclear Instruments and Methods, Vol. 213 (1983) 495-501. https://doi.org/10.1016/01675087(83)90447-7

[4] K. Naguib, M. Adib, Attenuation of thermal neutrons by an imperfect single crystal, Journal of Physics D: Applied Physics, Vol. 29 (1996) 1441-1445. https://doi.org/10.1088/00223727/29/6/005

[5] M. Koleška, Z. Lahodová, J. Šoltés, L. Viererbl, J. Ernest, M. Vinš, J. Stehno, Capabilities of the LVR-15 research reactor for production of medical and industrial radioisotopes, J. Radioanal. Nucl. Chem., Vol. 305, (2015) 51-59. https://doi.org/10.1007/s10967-015-4025-5

[6] J. Šoltés, L. Viererbl, J. Vacík, I. Tomandl, F. Krejčí, J. Jakůbek, The new facility for neutron radiography at the LVR-15 Reactor, Conference ECNS 2015, Journal of Physics: Conference Series 746 (2016) 012041. https://doi.org/10.1088/1742-6596/746/1/012041

[7] L. Viererbl, J. Šoltés, M. Vinš, Z. Lahodová, V. Klupák, Measurement of thermal neutron beam parameters in the LVR-15 research reactor, Transaction of 15th IGORR Conference, 13-18 October 2013, Deajeon, South Korea (2013).

[8] ASTM E181-10, Standard Test Methods for Detector Calibration and Analysis of Radionuclides (2010).

[9] ASTM E944-08, Standard Guide for Application of Neutron Spectrum Adjustment Methods in Reactor Surveillance (2008). 